\title{
Influência de Agaricus blazei Murrill sobre o tumor sólido de Ehrlich e linfonodos poplíteos de camundongos
}

\author{
[Influence of Agaricus blazei Murrill in solid Ehrlich tumor and popliteal \\ lymph nodes in mice] \\ D. Verçosa Junior ${ }^{1}$, M.M. Melo ${ }^{1 *}$, G.D. Cassali ${ }^{2}$, A.M. Dantas-Barros ${ }^{3}$, P.G.P. Silva Junior ${ }^{1}$ \\ ${ }^{1}$ Escola de Veterinária - UFMG \\ Caixa Postal 567 \\ 30123-970 - Belo Horizonte, MG \\ ${ }^{2}$ Instituto de Ciências Biológicas - UFMG - Belo Horizonte, MG \\ ${ }^{3}$ Faculdade de Farmácia - UFMG - Belo Horizonte, MG
}

\begin{abstract}
RESUMO
Estudou-se a influência do tratamento diário com filtrado aquoso de Agaricus blazei Murrill (ABM) $(25 \mathrm{mg} / \mathrm{ml})$, via oral, por 17 e 57 dias, em camundongos inoculados com tumor sólido de Ehrlich (TSE) por meio da curva de crescimento tumoral, do peso relativo do tumor, da contagem de regiões organizadoras de nucléolos (AgNORs) e dos padrões histológicos das massas tumorais e linfonodos poplíteos. Os animais que ingeriram o extrato aquoso do ABM por 57 dias apresentaram menor $(\mathrm{P} \leq 0,05)$ crescimento do TSE, no segundo e terceiro dias, fase inflamatória do crescimento tumoral. Quanto ao peso relativo das massas tumorais, valores de AgNORs, padrões morfoistopatológicos do TSE e ocorrência de processos metastáticos, não houve alteração significativa $(\mathrm{P}>0,05)$ entre os animais tratados e não tratados.
\end{abstract}

Palavras-chave: camundongo, Agaricus blazei, tumor de Ehrlich, histopatologia

\begin{abstract}
The influence of daily administration of Agaricus blazei Murrill (ABM) aqueous solution (25mg/ml) during 17 and 57 days in mice bearing solid Ehrlich tumor was studied. Tumoral growth, tumoral and spleenic relative weights, nucleoly organization regions AgNORs values and tumor and popliteal lymph nodes histopathology were daily evaluated. The animals that received ABM during 57 days showed lower values $(\mathrm{P} \leq 0.05)$ of tumoral growth on second and third days after the period corresponding to the inflammatory phase of tumoral growth. The relative weight of the tumor and AgNORs values were similar $(\mathrm{P}>0.05)$ between treated and non-treated animals. No difference in microscopic evaluation of the tumors in treated and non-treated animals was seen and metastasis in popliteal nodes of the tumor occurred in all the animals.
\end{abstract}

Keywords: mice, Agaricus blazei, Ehrlich tumor, histopathology

Recebido em 27 de julho de 2005

Aceito em 23 de novembro de 2006

*Autor para correspondência (corresponding author)

E-mail: marília@vet.ufmg.br

Apoio: FAPEMIG - CNPq 


\section{INTRODUÇÃO}

As neoplasias, importantes afecções em humanos e animais domésticos, são responsáveis por elevadas taxas de mortalidade. Os tratamentos utilizados nas neoplasias, como os radioterápicos e quimioterápicos, têm efeitos colaterais indesejáveis e, muitas vezes, deficientes respostas terapêuticas. Portanto, há uma incessante busca de fármacos eficientes, que tenham baixa toxicidade e, conseqüentemente, causem o mínimo de efeitos colaterais (Withrow, 1998; Suffredini, 2002).

Foi demonstrado in vitro que o extrato total e os polissacarídeos isolados do cogumelo brasileiro Agaricus blazei Murrill (ABM) possuem ação antitumoral direta sobre o sarcoma 180 e, in vivo, diminuem sua implantação (Itho et al., 1997; Jiang et al., 1999; Lee et al., 2003).

Cobaias que receberam o extrato de Agaricus blazei via oral apresentaram aumento do número e da atividade de células natural killers (NK) e aumento nas titulações de IgM, IgG e interleucina $-1 \beta$ (Ohno et al., 2001).

Da mesma forma, Gennari et al. (2002), ao estudarem Agaricus sylvaticus como complemento terapêutico em pacientes portadores de câncer de mama, demonstraram aumento do número e atividade de células NK, concluindo que esse cogumelo promoveria maior atividade do sistema imunológico.

O tumor de Ehrlich, um tipo de tumor transplantável utilizado para avaliações experimentais, é uma neoplasia de origem epitelial maligna, correspondente ao adenocarcinoma mamário de camundongos, que cresce na forma sólida quando implantado por via subcutânea (Dagli, 1989; Dagli et al., 1992a; Dagli et al., 1992b).

Como não existem estudos sobre as ações terapêuticas antineoplásica e antimetastática do $\mathrm{ABM}$ in natura em diferentes fases do crescimento do tumor de Ehrlich, objetivou-se avaliar os efeitos da administração do ABM sobre o crescimento tumoral, o padrão histológico e proliferativo do tumor de Ehrlich e a existência de metástases no linfonodo poplíteo utilizando como modelo experimental o camundongo.

\section{MATERIAL E MÉTODOS}

Todos os procedimentos realizados neste experimento foram avaliados pelo Comitê de Ética para Experimentação Animal da Universidade Federal de Minas Gerais (CETEA/UFMG).

Foram utilizados 30 camundongos da linhagem Swiss, fêmeas, não isogênicas, com 60 dias de idade, pesando entre 25 e $30 \mathrm{~g}$, provenientes do Biotério do Instituto de Ciências Biológicas da UFMG. Esses animais permaneceram durante o tempo de experimentação em três gaiolas, contendo 10 animais cada, sendo alimentados com ração comercial balanceada à vontade $\mathrm{e}$ submetidos ao controle artificial de ciclos de luminosidade (12 horas de luz/12 horas de escuro).

Os animais, separados aleatoriamente em três grupos experimentais (A, B e C), receberam os seguintes tratamentos: $\mathrm{A}$ - água durante todo o período experimental; $\mathrm{B}$ - filtrado de $\mathrm{ABM}$ por 17 dias e $\mathrm{C}$ - filtrado de ABM por 57 dias.

A amostra comercial do cogumelo utilizado foi adquirida na cidade de Nova Lima (MG). Parte dela foi enviada para identificação e depósito no Departamento de Botânica da UFMG sob o número BHCB90431. O restante da amostra foi triturado a 40mesh e mantido em vidro âmbar, previamente esterilizado, armazenado em local seco e abrigado da luz.

Diariamente era preparada uma solução aquosa $(25 \mathrm{mg} / \mathrm{ml})$ do cogumelo, realizadas extrações em banho-maria $^{1}$ a $60^{\circ} \mathrm{C} / 15 \mathrm{~min}$ e $25^{\circ} \mathrm{C} / 105 \mathrm{~min}$, filtragem em papel filtro ${ }^{2}$, para obtenção do filtrado $\mathrm{ABM}$, fornecido em substituição à água, em bebedouros de $75 \mathrm{ml}$ para os animais dos tratamentos B e C, diariamente, durante 17 e 57 dias, respectivamente.

Foram inoculados $0,05 \mathrm{ml}$ de solução contendo $2,5 \times 10^{6}$ células viáveis de tumor de Ehrlich provenientes do Departamento de Patologia Geral da UFMG, entre os coxins plantares do membro posterior esquerdo de todos os animais,

${ }^{1}$ Banho-maria Biomatic ${ }^{\circledR}$ - Aparalhos Científicos Ltda; $\mathrm{RS} /$ Brasil - Escala de 0 a $120^{\circ} \mathrm{C}$.

${ }^{2}$ Papel Filtro Qualy - J. Prolab, Comercio de Produtos Laboratoriais; Pr/Brasil; Raio: $6 \mathrm{~cm}$ de raio; Espessura: $205 \mu \mathrm{m}$; Poros: $14 \mu \mathrm{m}$. 
obtendo-se, assim, a implantação do tumor sólido de Ehrlich (TSE), conforme protocolo proposto por Guerra (1983). Os animais foram mantidos com o tumor durante 17 dias.

Foram realizadas mensurações em triplicata da espessura dorso-plantar dos membros posteriores direito e esquerdo dos animais com o auxílio de micrômetro de precisão ${ }^{3}(0,005 \mathrm{~cm})$ antes (um dia antes) e diariamente após a inoculação das células tumorais até o $17^{\circ}$ dia. Os valores médios obtidos diariamente para o membro posterior direito foram subtraídos dos obtidos para o posterior esquerdo do mesmo animal. O resultado foi considerado como sendo o valor do crescimento tumoral do dia.

No $57^{\circ}$ dia de experimento, os camundongos foram anestesiados com solução de quetamina ${ }^{4}$ $(50 \mathrm{mg} / \mathrm{g})$ e xilazina $^{5}(50 \mathrm{mg} / \mathrm{kg})$ por via intramuscular e sacrificados por deslocamento cervical. À necropsia, foram retirados os linfonodos poplíteos e os coxins plantares direito e esquerdo mediante desarticulação dos membros na junção tíbio-társica.

Os membros posteriores direito (sem tumor) e esquerdo (com tumor) foram pesados em balança eletrônica ${ }^{6}$ de precisão. Do valor do peso total do membro com tumor foi subtraído o valor do peso do membro sem tumor. Os resultados foram divididos pelo peso do animal, obtido após eutanásia, dando origem a valores considerados como peso relativo do tumor de cada animal.

Os linfonodos poplíteos direito e esquerdo e as massas tumorais foram separados dos membros, cortados transversalmente e processados pela técnica rotineira de inclusão em parafina (Prophet et al., 1992). Os cortes foram corados com hematoxilina-eosina e examinados por microscopia de luz.

Com o objetivo de qualificar a proliferação das células neoplásicas, cortes de massa tumoral foram coradas utilizando-se mistura de solução aquosa de nitrato de prata $^{7}$, segundo técnica descrita por Alves et al. (1999). As lâminas foram avaliadas em microscopia de luz (aumento de $1000 x$, e realizadas a caracterização morfológica e a contagem de regiões coradas pela prata (AgNORs). Foram contadas as AgNORs presentes em 30 núcleos de células neoplásicas escolhidas aleatoriamente, com o objetivo de se obter uma avaliação quantitativa do potencial proliferativo das células, (Silva et al. 2006).

A análise de variância foi feita levando-se em conta um delineamento inteiramente ao acaso empregando-se o programa SAS (User's ..., 1985). As médias foram comparadas utilizandose o teste Dunkan, com nível de significância de 5\%, segundo Sampaio (1998), excetuando-se os resultados obtidos das avaliações descritivas, observadas nas de leitura das lâminas histológicas.

\section{RESULTADOS E DISCUSSÃO}

Os animais do grupo $\mathrm{C}$, no segundo dia de observação, mostraram menor crescimento tumoral $(\mathrm{P} \leq 0,05)$, quando comparados aos grupos A e B. Todavia, no terceiro dia, essa diferença somente se manteve em relação ao grupo A $(\mathrm{P} \leq 0,05)$. A partir do quarto dia de experimento, não houve diferença entre os grupos (Fig. 1).

Segundo Dagli (1992a) e Dagli (1992b), nas primeiras 48 horas após inoculação tumoral, ocorrem respostas inflamatórias locais causadas, em grande parte, pelo trauma mecânico da inoculação e não propriamente pela presença das células tumorais. Possivelmente o extrato aquoso de ABM diminuiu a reação inflamatória local, expressa pela menor espessura dorso-plantar dos camundongos.

$\mathrm{Na}$ necropsia, os tumores, independente da utilização ou não de tratamentos com ABM, apresentaram-se semelhantes, esbranquiçados e infiltrados nos tecidos adjacentes. Da mesma forma, foram observados aumentos de volume dos linfonodos poplíteos esquerdos (lado da inoculação tumoral), quando comparados com os mesmos órgãos contra-laterais.

\footnotetext{
${ }^{3}$ Micrômetro Starrett. $\mathrm{n}^{\circ} 436-25 \mathrm{~mm}$

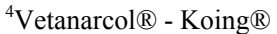

${ }^{5}$ Rompum ${ }^{\circledR} 2 \%$ - Bayer ${ }^{\circledR}$

${ }^{6}$ Eletronic Balance - Bioprecisa-FA2104N.

${ }^{7}$ Nitrato de Prata - Merck, Darmstadt.
} 


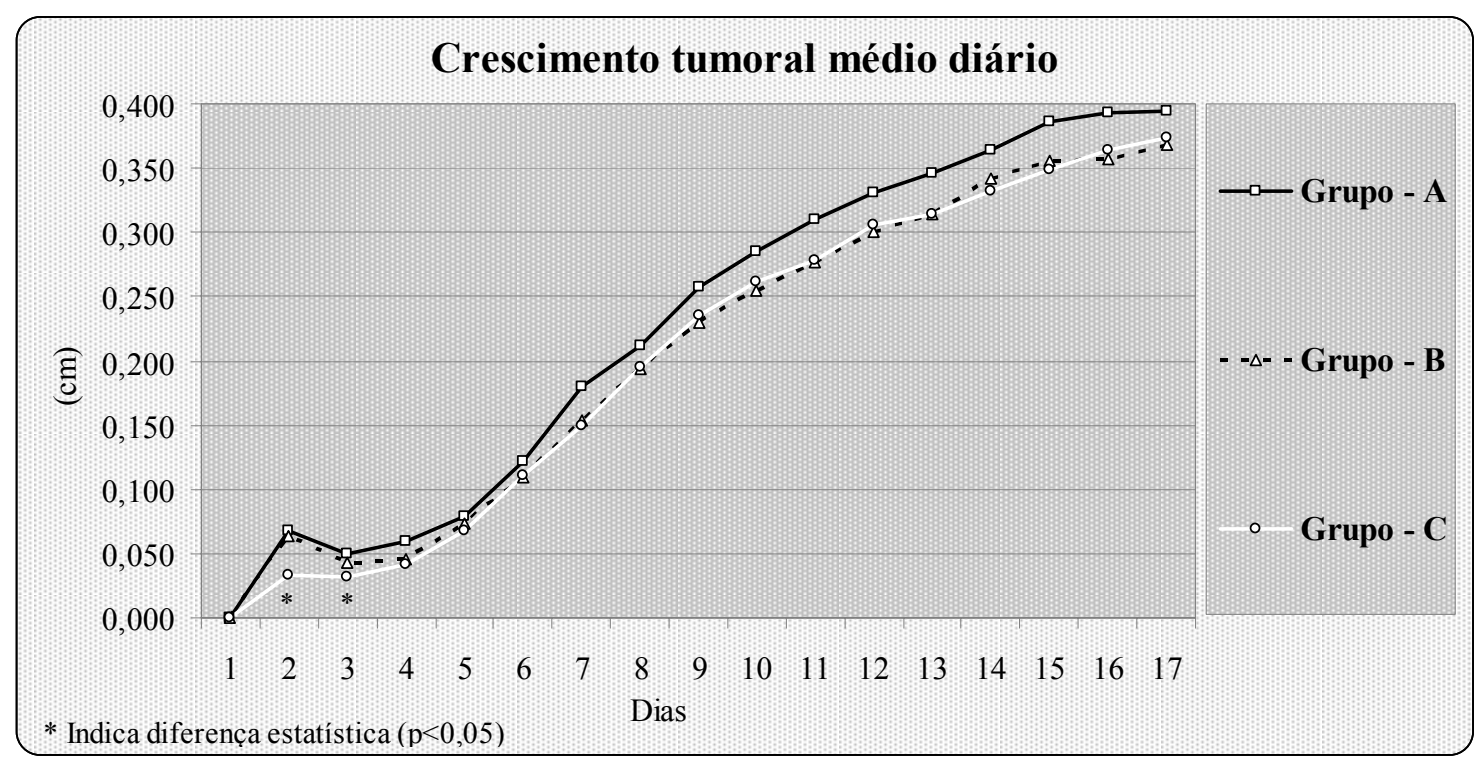

Figura 1. Curva de crescimento tumoral $(\mathrm{cm})$ do primeiro ao $17^{\circ}$ dia pós-inoculação tumoral de camundongos portadores de tumor sólido de Ehrlich, tratados com água (grupo A) ou com Agaricus blazei Murrill por 17 dias (grupo B) ou 57 dias (grupo C).

Nas avaliações microscópicas dos tumores, não foram observadas diferenças na morfologia das neoplasias entre os grupos, sendo visualizado estroma delicado, grandes áreas de necrose, maior concentração de células neoplásicas em áreas próximas aos vasos sangüíneos e pequena quantidade de infiltrado inflamatório. As células tumorais encontravam-se distribuídas aleatoriamente, no tecido, com grande pleomorfismo, alto grau de anaplasia, núcleos evidentes, numerosos, arredondados e apresentando uma relação núcleo/citoplasma muito maior que as células normais. Foram visualizadas células em padrões característicos de apoptose semelhantes aos padrões dessa neoplasia descritos em Guerra (1983), Dagli (1989) e Dagli et al. (1992a;b).

Estudos relatam a correlação entre a quantidade de células inoculadas no coxim plantar e sua presença nos linfonodos poplíteos, que são órgãos de disseminação linfática espontânea para esse tumor (Dagli, 1992a; Dagli, 1992b). Como todos os animais apresentaram metástases nos linfonodos do membro esquerdo (inoculado com TSE), sugere-se que o extrato aquoso de ABM, nas doses utilizadas, não teve ação antimetastática. As células neoplásicas apresentaram-se com aspecto morfológico e em quantidades semelhantes em todos os grupos, encontradas principalmente nas regiões subcapsulares, agrupadas ou em forma de cordões. Contudo, em nenhum animal foram observadas células neoplásicas nos linfonodos poplíteos do membro direito (sem tumor).

Como mostrado na Tab. 1, não foram observadas diferenças significativas $(\mathrm{P}>0,05)$ no peso relativo dos tumores entre os grupos, indiferente da presença e do tempo de tratamento com ABM.

Deve ser ressaltado que a avaliação do peso tumoral relativo realizada conforme o protocolo utilizado, está sujeita a um grande número de interferências, tais como a existência de processo inflamatório e de edemas nas regiões periféricas à massa tumoral, que podem interferir na adequada avaliação do peso, não proporcionando uma aferição tão adequada quanto a mensuração diária.

Os valores médios de AgNORs foram semelhantes $(\mathrm{P}>0,05)$ entre os grupos (Tab.1), indicando que a administração do extrato aquoso de ABM não interferiu na atividade nuclear e conseqüente potencial proliferativo do TSE, diferentes do observado por Jiang et al. (1999) e Lee et al. (2003), em animais inoculados com células de sarcoma 180. 
Tabela 1. Média, desvio-padrão e coeficiente de variação dos valores do peso relativo tumoral ( $\mathrm{g}$ ) e da média de AgNORS (unidades) em lâminas das neoplasias de camundongos portadores de tumor sólido de Ehrlich tratados com água (A), Agaricus blazei Murrill por 17 dias (B) ou 57 dias (C)

\begin{tabular}{ccc}
\hline Grupo & Peso relativo do tumor $(\mathrm{g})$ & Média de AgNORS (unidade) \\
\hline A & $0,21296 \pm 0,06270$ & $16,75 \pm 2,87$ \\
B & $0,19600 \pm 0,05577$ & $14,85 \pm 3,42$ \\
C & $0,21783 \pm 0,09310$ & $14,67 \pm 2,62$ \\
CV & 35,227 & 20,023 \\
\hline
\end{tabular}

Não houve diferença entre os valores $(\mathrm{P}>0,05)$.

\section{CONCLUSÕES}

A utilização do extrato aquoso de $\mathrm{ABM}$ por 57 dias diminuiu o crescimento diário do TSE, somente no segundo e terceiro dias após inoculação das células neoplásicas. A utilização do extrato aquoso de $\mathrm{ABM}$ não alterou os valores de peso relativo $\mathrm{e}$ os padrões morfohistopatológicos tumorais, a presença de processos metastáticos e o potencial proliferativo da neoplasia.

\section{REFERÊNCIAS BIBLIOGRÁFICAS}

ALVES, V.A.; BACCHI, C.E.; VASSALO, J. Manual de Imuno-histoquimica. São Paulo: Sociedade Brasileira de Patologia, 1999. 270p.

DAGLI, M.L.Z. Disseminação linfática do tumor de Ehrlich: estudo esperimental. 1989. 148f. Dissertação (Mestrado em Medicina Veterinária) - Faculdade de Medicina Veterinária e Zootecnia, USP, São Paulo.

DAGLI, M.L.Z.; GUERRA, J.L.; SALDIVA, P.H.N. An experimental study on the lymphatic dissemination of the solid Ehrlich tumor in mice. Braz. J. Vet. Res. Anim. Sci., v.29, p.97-103, 1992a.

DAGLI, M.L.Z.; SOMA, M.; GUERRA, J.L. et al Lymphatic dissemination in neoplasia: determination of nuclear volume and DNA content of primitive and regional lymph node Ehrlich tumor cells. Braz. J. Vet. Res. Anim. Sci., v.29, p.267-2671, 1992 b.

GENNARI, J.L.; VERONESI, R.; GENNARI, M.S. Uso do cogumelo Agaricus sylvaticus como complemento terapêutico em pacientes com câncer de mama e metástase pulmonar. Rev. Bras. Med., v.59, p.537-538, 2002.

GUERRA, J.L. Aspectos do processo inflamatório em camundongos portadores de Tumor de Ehrlich. 1983. 87f. Tese (Doutorado) - Faculdade de Medicina Veterinária e Zootecnia, USP, São Paulo.
ITHO, H.; SHIMURA, K.; KAWADEM A.M. Antitumor effects of a new polysaccharide-protein complex (ATOM) prepared from Agaricus blazei (Iwade Strain 101) "Himematsutake" and its mechanismis in tumor-bearing mice. Anticancer Res., v.17, p.277-284, 1997.

JIANG, S.M.; XIAO, Z.M.; XU, Z.H. Inhibitory activity of polysaccharide extracts from three kinds of edible fungi on proliferation of human hepatoma SMMC-7721 cell and mouse implanted S180 tumor. World J. Gastroenterol., v.5, p.404-407, 1999.

LEE, Y.L.; KIM, H.J.; LEE, M.S. et al. Oral administration of Agaricus blazei (H1 Strain) inhibited tumor growth in a sarcoma 180 inoculation model. Exp. Ambn., v.52, p.371-375, 2003.

OHNO, N.; FURUKAWA, M.; MINURA, N.N. et al. Antitumor beta glucan from the cultured fruit body of Agaricus blazei. Biol. Pharmac. Bull., v.24, p.820$828,2001$.

PROPHET, E.B.; MILLS, B.; ARRIGTON, J.B. AFIP Laboratory Methods in Histotechonology. Washington: American Registry of Pathology, 1992. $278 \mathrm{p}$.

SAMPAIO, I.B.M. Estatística aplicada à experimentação animal. Belo Horizonte: Fundação de Ensino e Pesquisa em Medicina Veterinária e Zootecnia, 1998. 221p.

SILVA, A.E.; F.G.A. SANTOS; G.D. CASSALI. Marcadores de proliferação celular na avaliação do crescimento do tumor sólido e ascítico de Ehrlich. Arq. Bras. Med. Vet. Zootec., v.58, p.658-661, 2006.

SUFFREDINI, I.B.A review the physiological basis of cancer diseases and the search for new chemotherapeutics. The importance of the Brazilian biodiversity. J. Inst. Health Sci., v.20, p.103-115, 2002.

USER'S guide: Statistics. 5.ed. Cary:SAS Institute, 1985. v.1, 956p.

WITHORW, S.J. Soft tissue sarcomas. Vet. Q., v.20, p.16-21, 1998. 